\title{
AGEING CALLS FOR SHORTER FULL-TIME TERTIARY EDUCATION AND INCREASED CONTINUING EDUCATION
}

Vincent Vandenberghe

\section{DISCUSSION PAPER | 2020 / 01}




\title{
Ageing Calls for Shorter Full-Time Tertiary Education and Increased Continuing Education
}

\author{
Vincent Vandenberghe*
}

January 16, 2020

\begin{abstract}
Population ageing requires a better-educated workforce capable of producing more of the goods and services consumed by a fast-rising number of old dependent individuals. At the same time, an ageing society badly needs its educated youth to rapidly become economically productive. In other words, the opportunity cost of educating young adults, particularly on a full-time basis, is on the rise. This paper argues that, in an ageing society, the challenge of policy-making is to find ways to foster education while limiting the time young adults spend in full-time tertiary education. In many countries, this probably implies compressing the theoretical duration of degrees (BA in 2 years instead of 3, MA in 4 years instead of 5) and introducing age-based financial incentives to reduce the time to graduation. For instance, the State subsidy (a grant) could be turned into an interest-charging loan beyond the age of 22 . In all countries, the challenge is also to rediscover the virtues of massive continuing/part-time/evening education : a formula that enables people who work to acquire/update skills at a very low opportunity cost. The financing of the direct costs of massive continuing education could take the form of State/employer-subsidised educational stipends granted to adults every 5 years beyond the age of 22 .
\end{abstract}

Keywords: Ageing, Time to Degree, Tertiary Education, Incentives

JEL Codes: I22, J1, H52

${ }^{*}$ Economics School of Louvain (ESL), IRES-LIDAM, Université catholique de Louvain (UCL), 3 place Montesquieu, B-1348 Belgium email: vincent.vandenberghe@uclouvain.be. This research was financially supported by the convention ARC No 18/23-088. 


\section{Context: demographic ageing, rising dependency}

The key macroeconomic challenge of population ageing is the decline of the number of people forming the working-age population $(W A P)$ relative to the total population $(P)$. Since labour remains the most important factor of production, the negative impact of population ageing on the level and growth rate of living standards is - in first approximation proportional to the decline of the share of the working-age population $\frac{W A P}{P}$. When it comes to living standards (i.e. income per head $\frac{Y}{P}$ ), at the very aggregate level, the key equation is indeed

$$
\frac{Y}{P}=\frac{Y}{W A P} \frac{W A P}{P}
$$

where $\frac{Y}{P}$ is fundamentally the product of productivity $\frac{Y}{W A P}$ and the working-age population ratio $\frac{W A P}{P}$. And it is that latter term that is mechanically (and negatively) impacted by ageing (Figure 1).

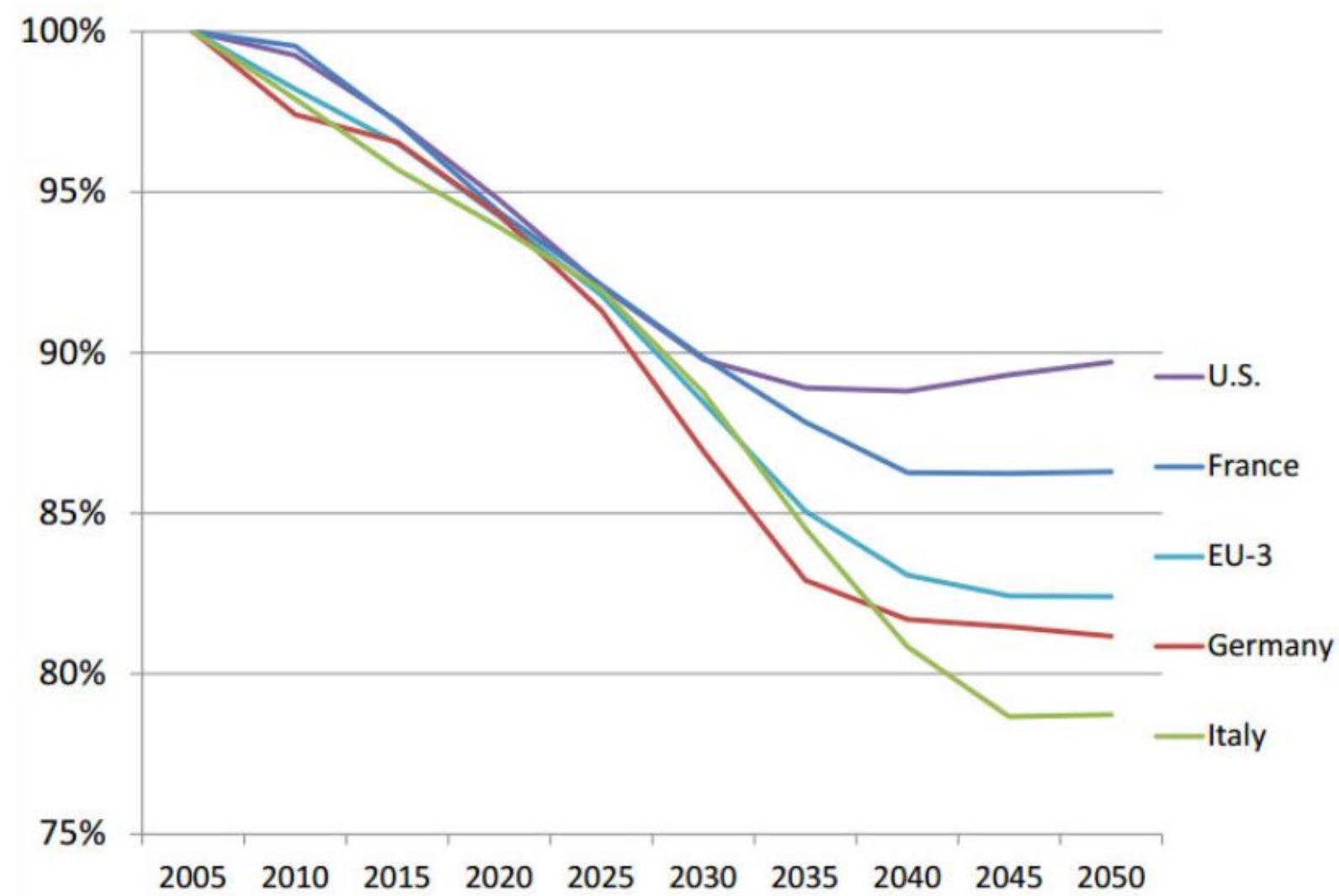

Figure 1: Projection of the evolution of working-age population (share of people aged 20-65 in total population, 100=200). Source: Börsch-Supan, 2014 


\section{The traditional approach to combating rising old de- pendency}

On second view, the statements made in Section 1 exemplify a common mistake : equating demography with economics, and assume that the supply of labour is fixed, that labour market and welfare institutions (pension systems...) do no change, and more generally that education/work/retirement sequences of life are immutable. Pessimistic statements based on Figure 1 underestimate what societies do when confronted to new challenges : adapt, evolve and reform. And indeed, relatively simple algebraic developments, applied to equation 1 and guided by standard economic analysis, are sufficient to show that many things adjust to compensate for contraction of the working-age population induced by demographic ageing.

One of them consists of revisiting the way we conceive the "working age".

The share of the working-age population $\frac{W A P}{P}$ - corresponding to the dashed segment in Figure 2 - should be regarded as a choice variable. The upper limit $\left(b^{u}\right)$ defining the working-age population (now generally set at 65) can be indexed to life expectancy (the total length of the line in Figure 2). OECD economists (Martins et al., 2005) have simulated the impact of such an indexation on the dependency ratio and conclude that this measure (with the possible exception of Japan) could completely eliminate the rise of dependency. In other words, conditional on minor variations in the youth dependency ratio, the measure would avoid either $i$ ) a substantial increase of contributions to finance pension schemes, or ii) a general reduction of the level of pensions benefits/annuities.

Note that the implicit or explicit indexation of the retirement age on life expectancy taking the form of a postponement of the statutory retirement age or an extension of the contribution periods opening up the full pension rights - is currently the main strategy pursued by most OECD countries to cope with the rising burden of dependency.

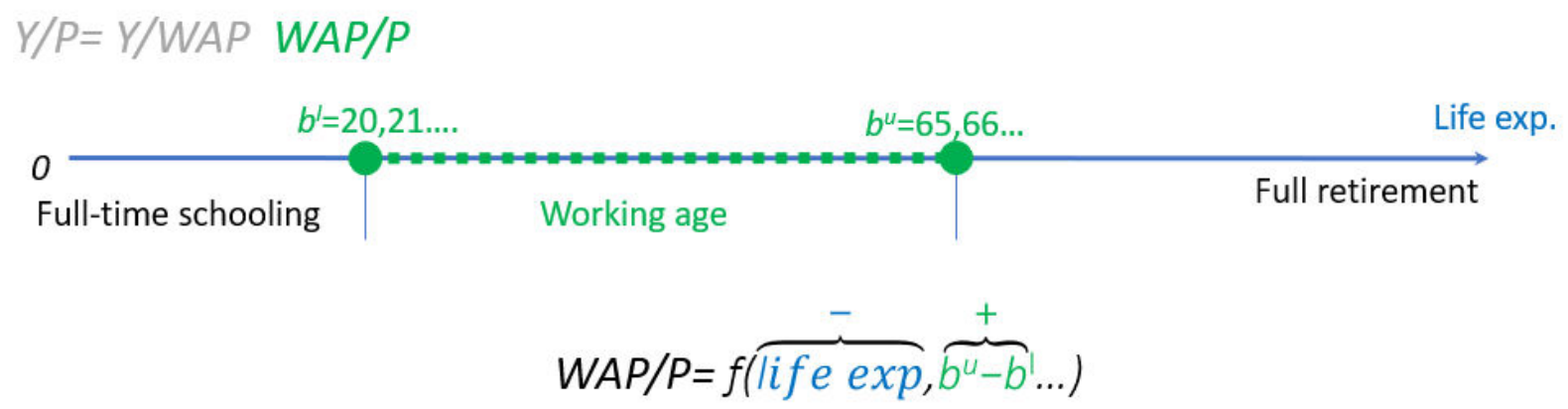

Figure 2: The share of the working-age population - a choice variable 


\section{The case for a greater focus on the duration of initial education}

\subsection{Longer studies are not necessarily a good thing}

As Figure 2 suggests, the share of life dedicated to work - and hence the level of the ratio $\frac{W A P}{P}$ - is also a function of the age of entry into the labour market. The latter is logically higher as young people devote more time to study; which is the trend observed in many countries in recent decades. The prevailing opinion is that such an extension, in a context of demographic ageing, is overall a good thing. It contributes to raising skills /human capital; one of the determinants of labour productivity (Lebedinski and Vandenberghe, 2014) which is none other than the term $\frac{Y}{W A P}$ in equation 1 , and whose growth is a priori key in counteracting the effects of ageing.

However, it is wrong to think that the prolongation of initial education is automatically synonymous with higher educational attainment/human capital (and, hence, labour productivity). Methodologically, one cannot equate "longer duration of education" with "higher degree", simply because individuals may take more or less time to complete a given degree. For the US, Bound, Lovenheim, and Turner, 2010 show that over the past three decades, the share of BA degree recipients that graduate within four years has decreased and, more generally, the length of time it takes college students to attain degrees has increased. Among researchers, however, the length of time to degree attainment has received little attention.

For Europe, we have no data on the evolution of the time to degree as such. But interesting information can be retrieved from the EU-SILC survey (see Appendix, Table 1 for descriptive statistics), as respondents declare both their highest degree and the age of completion of such a degree. For the period 2010-15, EU-SILC shows a huge heterogeneity in Europe as to the age at which a higher/tertiary degree is obtained (horizontal axis in Figure 3). This is puzzling. Why, on average, do Danish or Icelandic youth complete higher/tertiary education at the age of $27+$, whereas British or French young people finish it at just over the age of 23 ? The difference is considerable, ranging from 4 to 5 years where considering the extreme cases. And its implications on the proportion of people in employment (or the dependency ratio) are far from being insignificant, since higher education now involves about $50+\%$ of young age cohorts in most European countries. What is more, there is no positive correlation between the duration of studies and the proportion of 30-34 individuals with a higher degree (Figure 3, vertical axis; Table 2, models 1,2). While longer studies are costly — including in terms of dependency — there is no aggregate evidence that 
they favour the access to a tertiary education diploma.

Another way to assess the cross-country time-to-graduation heterogeneity is to examine its relationship with the wage premia. Economists will agree that what truly matters is the effect on wages; which, in a competitive labour market should reflect productivity. Does extra time spent on obtaining a given diploma — potentially synonymous with more indepth learning/teaching, as some observers would argue — result in a higher salary bonus ? Not really. Figure 4 even suggests the opposite, by displaying a negative and statistically significant correlation between the duration of studies and the gross wage premium (Table 2 . col.3).

Some observers would argue that older students have accumulated significant labour market experience as many of them hold student jobs : something that help them have a smoother and faster school-to-work transition, with less risk of unemployment episodes. In Denmark - a country known for having among the oldest students in the world — about $70 \%$ of those aged 23-24 have a student job. Yet, even more Australian students (85\%), for example, work but still manage to graduate at a much younger age (OECD, 2009).

Finally, what can be said about equity? Could it be that granting more time to complete a degree translates into more chance of access for youth from disadvantaged background ? Figure 5 depicts some tentative results based on cross-country evidence (the econometric results are to be found in Table 2, col.4). It combines data from the EU-SILC that we have used so far, and data from the European Social Survey (ESS). EU-SILC delivers the distribution of the age of graduation of young adults reported on the $x$ axis, while the values measured on the $y$ axis are from ESS. They quantify the degree of (in)equity as to the chance of acquiring a tertiary degree. ESS contains detailed information about respondents' educational attainment, but also that of their parents. We have used it to estimate a logit model separately for each country. This delivers the probability premium associated to having parents holding a tertiary degree (primary-educated parents form the reference category). The point is that results on display on Figure 5 are not supportive of the theory that extra time-to-degree leads to more equity.

In summary, there is no country-level evidence supportive of the idea that countries where young people spend more time in higher education reap economic benefits; on the contrary. The phenomenon of long studies comes at a cost - a private one, but also a social one in terms of postponed labour market entry and higher dependency ratio (i.e. a lower $\frac{W A P}{P}$ ratio in equation 1) - but it does not generate any gain in terms of human capital or productivity (i.e. a higher $\frac{Y}{W A P}$ ratio in equation 1 ). And it does also not seem to contribute to fostering equity of access to the tertiary degree. 


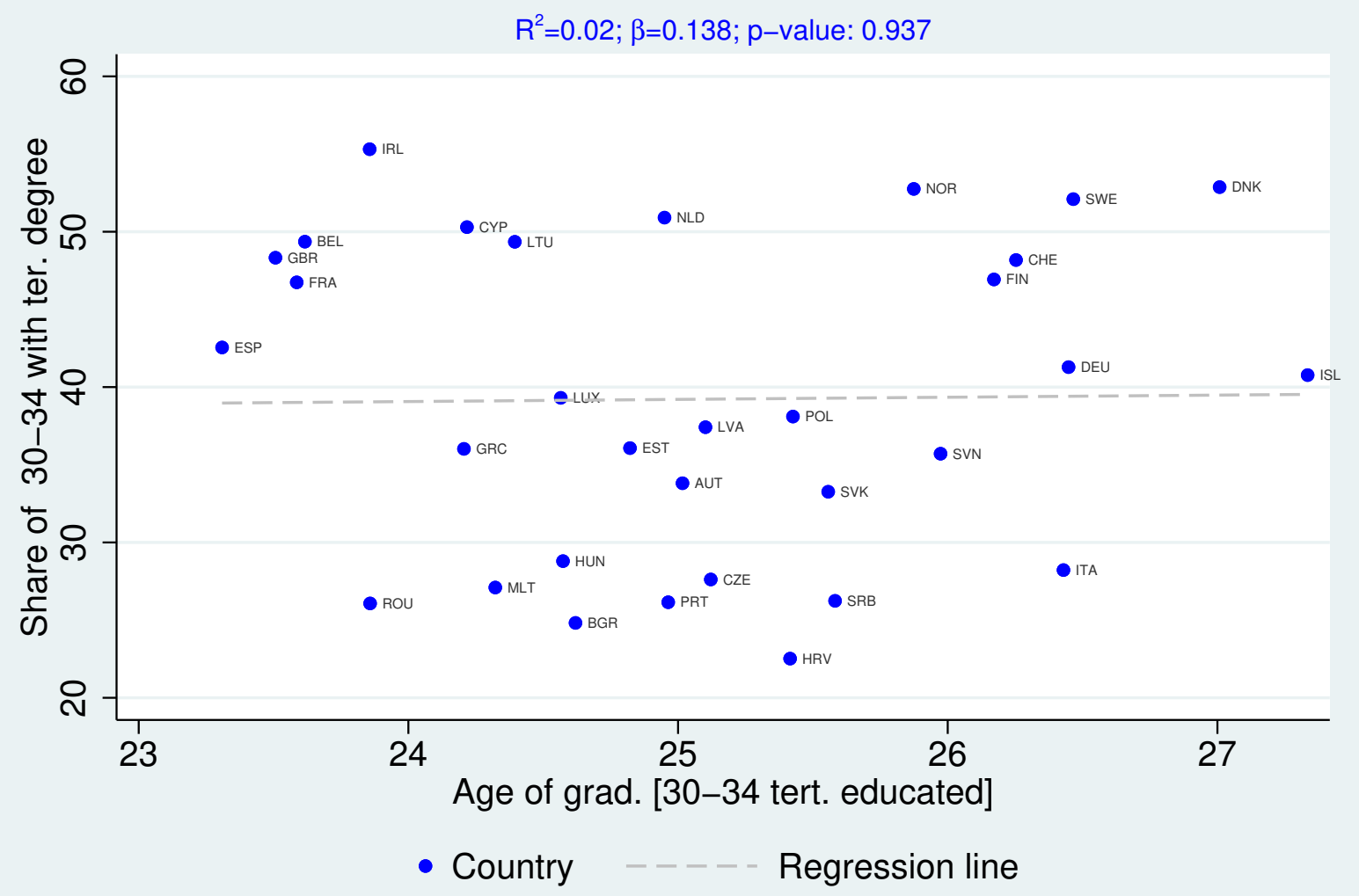

Source: EU-SILC 2010-15

Figure 3: Proportion of the population aged 30-34 with a tertiary degree \& age at which the diploma was obtained. See Appendix, Table 2 for detailed regression results. 


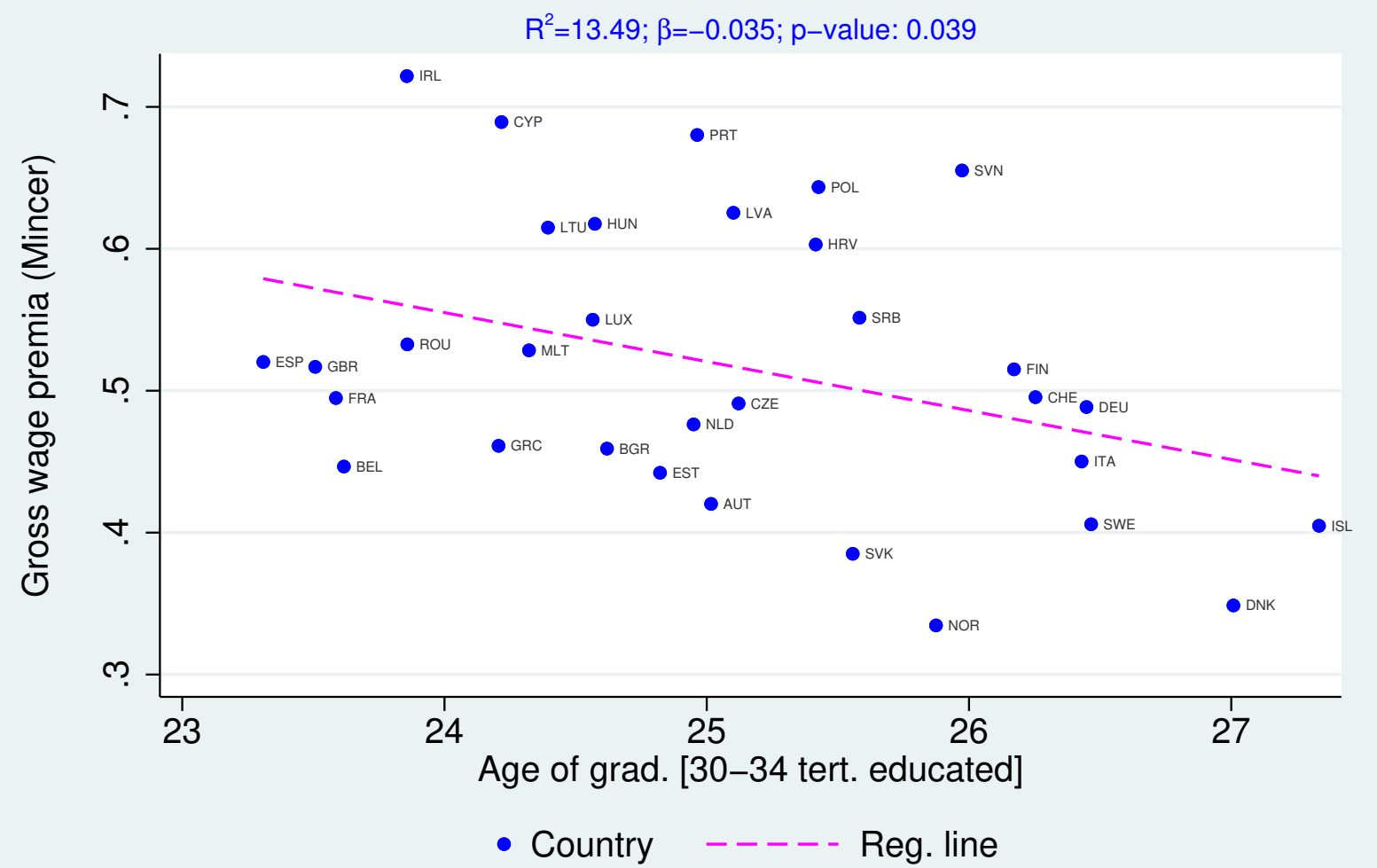

Source: EU-SILC 2010-15. Gross wage premia are estimated as Mincerian cat. rate of return Controls: exp, exp2, gender

Figure 4: Gross wage premium of persons aged 30-34 with a tertiary degree \& age of graduation for that degree. See Appendix, Table 2 for detailed regression results. 


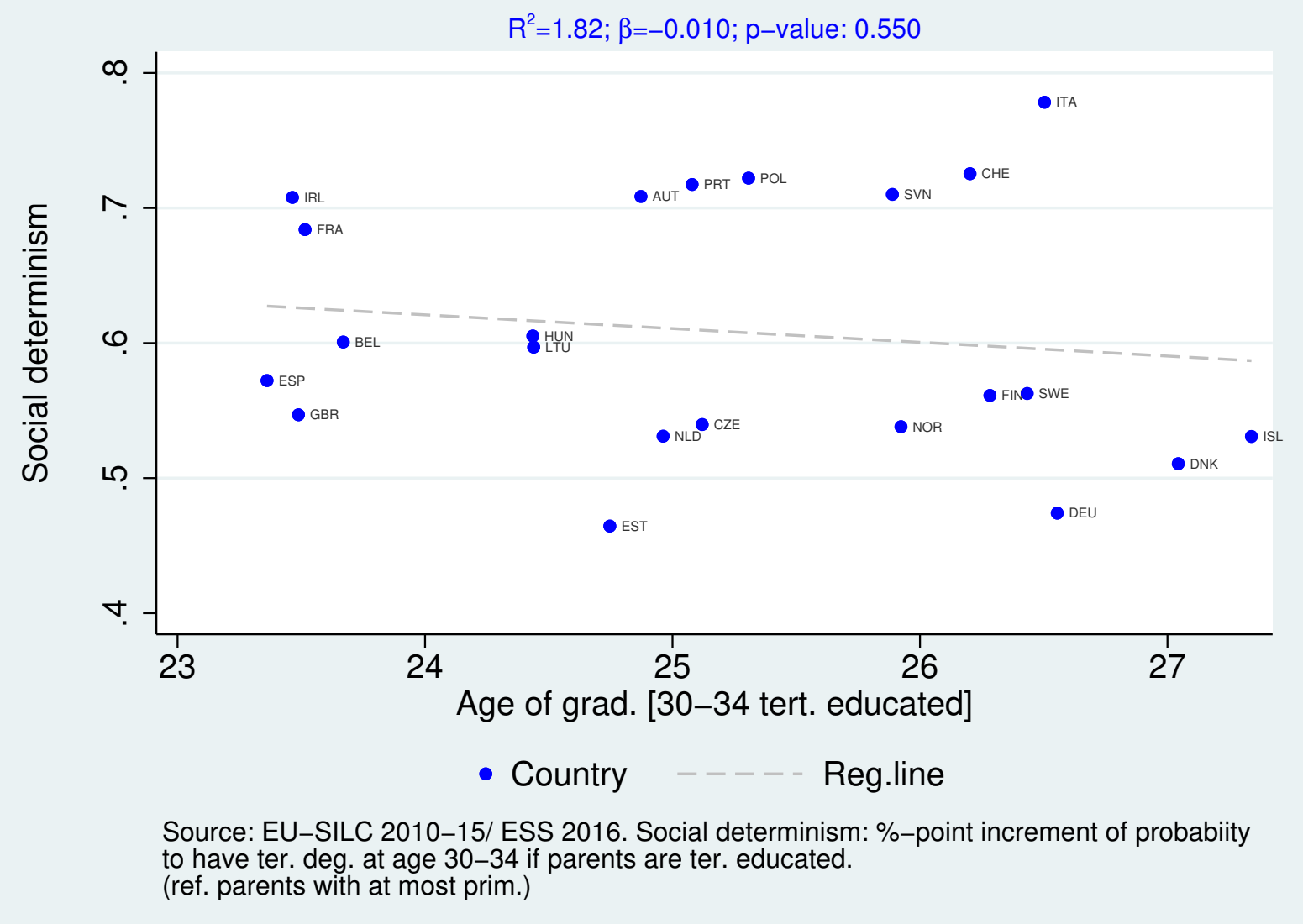

Figure 5: Social determinism (inequity) in access to tertiary degree \& age at which the diploma was obtained. See Appendix, Table 2 for detailed regression results.

\subsection{Age-based incentives towards shorter tertiary education}

Denmark is a case in point when it comes to discussing the duration of initial education. Alongside Iceland, it probably has among the oldest students in the world. And it is also one of the first European countries to have developed a policy explicitly aimed at reducing the time it takes to complete a degree.

In Denmark the delay starts at the end of compulsory education (i.e. 16). Indeed, long waits (due to gap years) already arise between the lower secondary and the upper secondary cycles. A similar phenomenon is observed at the articulation between upper secondary education and tertiary education. Moreover, within tertiary education Danish students frequently change study course, implying that they are older when they start the programme they eventually graduate from. Addressing this issue is challenging. There is no straightforward answer to the gap year phenomenon that is deeply rooted in the Danish culture. Beyond, possible options include a better command of core skills at the end of compulsory education to increase the level of "study readiness" of teenagers (to limit the 
need for time-consuming remedial programmes), or improved guidance at the entrance of universities (to limit the incidence of programme changes). But, invariably, the abnormally long duration of studies in Denmark brings up the question of the opportunity of enacting age-based incentives towards shorter initial education ; i.e. introducing financial incentives rewarding early start and completion of programmes, targeting both the students and the educational institutions they attend.

As early as 2006, in Denmark, some measures were announced to combat the late-studycompletion syndrome. One change consisted of making access to tertiary education easier if the student does not wait more than two years after completing upper secondary education. Under the new setting, such a student has her upper-secondary grade average multiplied by 1.08 , implying an easier access to studies where the number of places is limited by a numerus clausus. Measures aimed at changing the attitude of providers (i.e. tertiary education institutions) were also enacted in 2006. For instance, a certain percentage of the per student public financing to educational institutions is paid out only when students complete the exams. It is reduced prorata if the realised duration of programmes exceeds the theoretical one.

Another interesting country is the Netherlands. In 1996, "prestatiebeurs" (performance grant) became the corner stone of State student financing (i.e. the one aimed at covering subsistence costs of students). The system has been revised several times since, but the initial core idea remains. If Dutch students meet certain academic progress requirements, the performance-related grant is converted into a traditional student grant/allowance (i.e. a gift). If not, all financial support is considered a loan and must be repaid. The performancerelated grant provided in the first year of enrolment is converted into a grant if students validate a minimum of $50 \%$ of the credits. If they also obtain their degree within six years after first enrolment (seven for engineering students), the performance-related grant for the remaining years is converted into a grant.

Denmark and the Netherlands illustrate the rationale of developing a fully fledged "activation strategy" targeting students, but also the institutions in charge of educating them, with the explicit aim of enticing both sides to foster early start and reduce the average time it takes to complete a degree.

De facto, these policies constitute age-based incentives towards shorter initial education. And our prognosis is that, in great part due to ageing, more and more countries will implement these policies. This said, many questions remain. First, what may work in theory, may not work as a political programme. Misconceptions about the short-term costs and the long-term benefits of reforms aimed at reduced the average age of graduation may lead to backlash. Second, does the implementation of these policies make any differences ? The 
available data for Europe do not allow us to say anything robust about the outcomes of the Danish or Dutch reforms. Third, are the above policies compatible with anti-discrimination laws? These include protections for groups based on sex, race, ethnicity, nationality, sexual orientation, gender but also age. On the labour market, we are familiar with the idea that nobody should be treated less favourably, or not given the same opportunities, because he or she is considered to be too old or too young. Would the same ban apply to education ? But it remains to be seen whether what the Danes or the Dutch educational authorities do qualify as an age-based policy. Our interpretation is that these policies set up incentives to reduce the "duration" of studies, or that of transition spells characterising an education trajectory ; for example, between secondary and tertiary education. And even if longer duration of studies and age are statistically correlated, they need not to be in principle.

\subsection{Rediscovering the merits of adult/continuing education}

Population ageing requires a better-educated workforce capable of producing more of the goods and services that are consumed by a fast-rising number of old dependent individuals. At the same time, an ageing society badly needs its educated youth to rapidly become economically productive. In other words, the opportunity cost of educating young adults, particularly on a full-time basis, is higher today than it was some decades ago. And it is likely to rise in the future.

In such a context, reducing time to graduation in traditional educational institutions is fine, but probably more can be done. The challenge, of course, remains the question of dependency and that of the rising opportunity cost of maintaining people away from work. The good news is that there are educational institutions and programmes that are characterised by a much lower opportunity cost than traditional universities. Ageing will probably force our societies to rediscover their merits.

A careful examination of educational institutions reveals an unsuspected degree of diversity that the recent uniformisation zeal of decision-makers has not completely erased. Many providers of post-secondary forms of education were set up on a rather different model than universities. Some have their roots in the medieval system of apprenticeship. Others date back from the industrial era and - under the auspices of unions or socially conscious employers - were designed to serve the need of poor/adult students who needed to pursue full-time employment. Key to their model is the offering of classes at night and on weekends. In such cases, students do no forego any net salaries, and the public any income tax revenues, leading to tremendous savings in educational costs.

We would suggest that is time to rediscover the virtues of a model where younger gen- 
erations complete their full-time initial education at a relatively young age (say 21 or 22), followed by an accelerated entry into the labour force. Then, the norm would be to attend a massified system of continuing/part-time or evening education, whose financing could take the form of State/employer-subsidised educational stipends, granted every 5 years beyond the age of 22 .

\section{Conclusion}

By 2050, the proportion of over-60s is expected to increase to a third of the population in developed countries. Reflecting mainly the lengthening of life expectancy, these figures represent an extraordinary progress of civilisation. But they also point to serious challenges, including maintaining a sufficient proportion of active individuals. As labour remains the main source of production of goods and services, the impact of ageing on living standards is, in first approximation, proportional to the decline in the share of the population at work. And statisticians predict that the cumulative decline could range from 10 to $22 \%$ by 2050 , compared to the reference year of 2005. Fortunately, it is possible to compensate for the negative effect of ageing on the overall volume of work accomplished in an economy. The increase in life expectancy is accompanied by an increase in healthy life expectancy $(+2.4$ years per decade since the beginning of the $19^{\text {th }}$ century). This would suggest that the most natural response to ageing is to raise the statutory retirement age, by explicitly or implicitly indexing it on life expectancy. However, it would be wrong to see it as the only way to compensate for the effects of ageing on the proportion of people in employment.

Indeed, German researchers (Börsch-Supan, 2014) show numerically that it is possible, for Europe by 2050, to fully offset the negative effects of ageing by postponing the exit from the labour market by two years, but also - and this is the originality of their approach by using three other levers: i) reducing the duration of initial schooling, ii) aligning women's participation in the labour market with that of men and iii) increasing the annual working time per worker by $5 \%$.

The diversity and nature of these proposals may come as a surprise, given the tendency to focus the debate exclusively on the postponement of retirement. Let us consider more carefully the idea of lowering the age of entry into the labour market and reducing the duration of higher education in the case French-speaking Belgium. From the mid-1980s, for BA programmes, the theoretical duration was raised from 2 to 3 years. More recently, the Bologna reform has established the 5-year Master's degree as the reference for anyone attending university. But the study of wage premiums does not indicate that the skill level of those who took 3 or 5 years to graduate is now significantly higher than that of those 
who previously graduated in 2 or 4 years. The only effect of longer studies in Frenchspeaking Belgium seems to have been to increase the private cost of education and that for the State in terms of foregone taxes and social security contributions, and to reduce the employment rate among the under-26's. During the same period of time, decision-makers spent a lot of political capital to enact reforms aimed at increasing the employment rate beyond the age of 55. Perhaps time has come to reverse the trend to ever-longer initial education and consider reducing the time it takes students to attain degrees. Invariably, this raises the question of the introduction of age-based financial incentives towards shorter initial education ; targeting both students and educational institutions. And the corollary is to develop upskilling opportunities based on the model of part-time/evening/continuing education.

\section{References}

Börsch-Supan, Axel (2014). Aging Societies: Individual and Societal Plasticity. MEA discussion paper series 201422. Munich Center for the Economics of Aging (MEA) at the Max Planck Institute for Social Law and Social Policy.

Bound, John, Michael F Lovenheim, and Sarah Turner (2010). Increasing Time to Baccalaureate Degree in the United States. Working Paper 15892. National Bureau of Economic Research.

Lebedinski, Lara and Vincent Vandenberghe (2014). "Assessing education's contribution to productivity using firm-level evidence". In: International Journal of Manpower 35.8, pp. 1116-1139. URL: https://ideas .repec .org/a/eme/ijmpps/v35y2014i8p11161139.html.

Martins, Joaquim Oliveira et al. (2005). The Impact of Ageing on Demand, Factor Markets and Growth. OECD Economics Department Working Papers 420. OECD Publishing. OECD (2009). Jobs for Youth: Australia. OECD, Paris. 


\section{Appendix}


Table 1: EU-SILC, ESS: descriptive statistics (2010-15)

\begin{tabular}{|c|c|c|c|c|c|c|c|}
\hline & $\begin{array}{l}\text { Share } \\
30-34^{\mathrm{a}}\end{array}$ & $\begin{array}{l}\text { Age } \\
\text { grad. }^{\text {b }}\end{array}$ & $\begin{array}{c}\text { Mincer } \\
\text { wage prem. }\end{array}$ & $\begin{array}{c}\text { Social } \\
\text { determ. }^{c}\end{array}$ & $\begin{array}{c}\text { GDP } \\
\text { cap.(th€) }\end{array}$ & $\begin{array}{c}\text { GDP } \\
\text { empl.(th€) }\end{array}$ & $\begin{array}{c}\text { Capital } \\
\text { intens.(th€) }\end{array}$ \\
\hline AUT & 33.81 & 25.02 & 0.42 & 0.71 & 41.27 & 81.20 & 371.99 \\
\hline BEL & 49.36 & 23.62 & 0.45 & 0.60 & 37.87 & 87.23 & 441.52 \\
\hline BGR & 24.82 & 24.62 & 0.46 & - & 15.17 & 30.68 & 78.78 \\
\hline $\mathrm{CHE}$ & 48.18 & 26.25 & 0.50 & 0.73 & 58.66 & 97.75 & 343.15 \\
\hline CYP & 50.30 & 24.22 & 0.69 & - & 26.43 & 71.93 & 406.10 \\
\hline CZE & 27.62 & 25.12 & 0.49 & 0.54 & 26.44 & 55.28 & 325.83 \\
\hline $\mathrm{DEU}$ & 41.28 & 26.45 & 0.49 & 0.47 & 42.90 & 83.68 & 325.85 \\
\hline DNK & 52.87 & 27.01 & 0.35 & 0.51 & 43.32 & 87.12 & 390.00 \\
\hline ESP & 42.55 & 23.31 & 0.52 & 0.57 & 31.21 & 77.98 & 435.77 \\
\hline $\mathrm{EST}$ & 36.07 & 24.82 & 0.44 & 0.46 & 22.31 & 49.00 & 229.65 \\
\hline FIN & 46.93 & 26.17 & 0.52 & 0.56 & 37.71 & 78.92 & 387.86 \\
\hline FRA & 46.74 & 23.59 & 0.49 & 0.68 & 36.51 & 88.06 & 413.20 \\
\hline GBR & 48.33 & 23.51 & 0.52 & 0.55 & 35.09 & 74.69 & 329.45 \\
\hline GRC & 36.02 & 24.21 & 0.46 & - & 23.95 & 60.70 & 368.05 \\
\hline HRV & 22.52 & 25.42 & 0.60 & - & 19.59 & 54.56 & 250.81 \\
\hline HUN & 28.80 & 24.57 & 0.62 & 0.61 & 20.75 & 51.52 & 234.12 \\
\hline IRL & 55.31 & 23.86 & 0.72 & 0.71 & 48.89 & 123.30 & 494.76 \\
\hline ISL & 40.77 & 27.33 & 0.40 & 0.53 & 37.03 & 68.08 & 288.79 \\
\hline ITA & 28.22 & 26.43 & 0.45 & 0.78 & 34.45 & 85.37 & 487.08 \\
\hline LTU & 49.35 & 24.39 & 0.61 & 0.60 & 20.74 & 57.76 & 204.49 \\
\hline LUX & 39.31 & 24.57 & 0.55 & - & 53.41 & 72.40 & 417.07 \\
\hline LVA & 37.42 & 25.10 & 0.63 & - & 18.81 & 47.78 & 313.33 \\
\hline MLT & 27.10 & 24.32 & 0.53 & - & 24.18 & 57.89 & 222.33 \\
\hline NLD & 50.91 & 24.95 & 0.48 & 0.53 & 44.04 & 83.40 & 372.30 \\
\hline NOR & 52.75 & 25.87 & 0.33 & 0.54 & 81.20 & 152.55 & 427.50 \\
\hline POL & 38.10 & 25.43 & 0.64 & 0.72 & 21.81 & 54.28 & 122.26 \\
\hline PRT & 26.15 & 24.96 & 0.68 & 0.72 & 24.74 & 57.08 & 374.91 \\
\hline $\mathrm{ROU}$ & 26.07 & 23.86 & 0.53 & - & 17.41 & 42.99 & 186.48 \\
\hline SRB & 26.24 & 25.58 & 0.55 & - & 12.46 & 47.81 & 210.72 \\
\hline SVK & 33.26 & 25.56 & 0.39 & - & 22.57 & 56.35 & 193.94 \\
\hline SVN & 35.71 & 25.97 & 0.66 & 0.71 & 25.53 & 54.13 & 284.47 \\
\hline SWE & 52.10 & 26.47 & 0.41 & 0.56 & 41.70 & 86.09 & 342.51 \\
\hline
\end{tabular}

Source: EU-SILC, ESS

a:Share among 30-34 y.o. in possession of a tertiary degree.

${ }^{\mathrm{b}}$ :Age at which 30-34 respondents obtained their tertiary degree.

${ }^{\mathrm{c}}$ :Percentage-point increment of probability to have ter. deg. at age 30-34 if parents are ter. educated. 
Table 2: Age of graduation and outcomes. Country-level OLS regression results. Point estimate (std error).

\begin{tabular}{lcccc}
\hline \hline & $(1)$ & $(2)$ & $(3)$ & $(4)$ \\
& Share 30-34 $^{\mathrm{a}}$ & Share 30-34 $^{\mathrm{a}}$ & Wage premium $^{\mathrm{b}}$ & Soc.mob. $^{\mathrm{c}}$ \\
\hline Age grad. & 0.138 & -1.239 & $-0.035^{*}$ & -0.010 \\
& $(1.725)$ & $(1.264)$ & $(0.016)$ & $(0.017)$ \\
GDP per capita & & $1.018^{*}$ & & \\
& & $(0.436)$ & & \\
GDP per capita & & $-0.012^{*}$ & & \\
& & $(0.005)$ & & \\
GDP per empl. & & $0.388^{*}$ & & \\
& & $(0.152)$ & & \\
Capital intensity & & -0.032 & & \\
& & $(0.022)$ & & \\
\hline Nobs & 32 & 32 & & \\
Rsq & 0.00 & 0.61 & & \\
\hline \hline
\end{tabular}

Source: EU-SILC, ESS: 2010-2015

a:Share among 30-34 in possession of a tertiary degree.

b:Mincerian gross wage premium of 30-34 y.o. tertiary educated individuals [ref. primary edu.]. Controls comprise exp, exp ${ }^{2}$ and gender.

${ }^{c}$ :Percentage-point increment of probability to have ter. deg. at age 30-34 if parents are ter. educated. [ref. primary edu.] 


\section{INSTITUT DE RECHERCHE ÉCONOMIQUES ET SOCIALES}

Place Montesquieu 3

1348 Louvain-la-Neuve

ISSN 1379-244X D/2020/3082/01 